\title{
LLINATGES I PODER LOCAL A L'ALZIRA DEL SEGLE XV
}

\author{
LINEAJE AND LOCAL POWER IN FIFTEENTH-CENTURY ALZIRA
}

\section{SANDRA BERnABeu BorJa Universitat de València}

\begin{abstract}
Resumen: Estudio de base documental sobre el ejercicio de poder público municipal a la villa de Alzira a partir de la identificación exhaustiva de aquéllos que desarrollaron las principales magistraturas y cargos municipales a lo largo del siglo XV. El análisis diacrónico realizado a partir de las actas municipales o Libres d'acord dels Jurats e Consell entre 1388 y 1500 , conservadas en el Arxiu Municipal d'Alzira (AMA), permite observar el predominio de ciertos grupos familiares y su participación sobresaliente en la vida política local.
\end{abstract}

Palabras clave: Alzira, gobierno municipal, oligarquía local, siglo XV.

\begin{abstract}
Study based on archive documents about the exercise of local public power in the city of Alzira through a detailed identification of those people who developed the main political offices during the fifteenth century. The diachronic analysis, from 1388 to 1500 , based on municipal minutes taken from Libres d'acord dels Jurats e Consell, which is preserved in the Arxiu Municipal d'Alzira, shows the predominance of certain family groups and her outstanding participation in the local politics.
\end{abstract}

Keywords: Alzira, municipal government, local oligarchy, fifteenth-century.

1 El present estudi s'ha desenvolupat en el marc de la beca d'investigació Joves investigadors de la Ribera 2014, finançada per l'Exc. Ajuntament d'Alzira. Endavant AMA = Arxiu Municipal d'Alzira. 


\section{Introducció}

La transferència plena de les funcions de govern a la comunitat local té lloc al llarg de tota la geografia de la Corona d'Aragó a partir de la segona meitat del segle XIII. Un temps en què la monarquia, immersa en el procés d'expansió territorial, tractava de dirigir tots els seus esforços en recollir impostos, dins d'un context de desenvolupament de la fiscalitat i la hisenda local (Furió, 1996: 9-20; Mira i Viciano, 1996: 135-149; Sánchez, 2003: 427-459). Al regne de València, la política municipalista de Jaume I va consistir en l'extensió progressiva del costum de la ciutat de València a tots els territoris de reialenc, el que va suposar que des de ben aviat les ciutats i viles del regne imitaren a grans trets l'organització sociopolítica de la capital (Narbona, 2013: 579-588). Aquest fou el cas de la vila d'Alzira, que va adquirir el seu règim municipal en 1249 quan Jaume I va atorgar la jurisdicció d'aquesta i del seu terme a tots els prohoms i habitants d'aquella (Huici, 1916: 487-488).

Com ja ha mostrat la historiografia, Alzira va ser una de les viles més importants del regne de València, en tant que considerada el quart nucli poblacional del regne amb al voltant de 1.600 focs per al període comprés entre 1375 i 1418, que la situen únicament per sota dels 8.000 focs de la ciutat de València i dels 3.000 focs aproximadament de la ciutat de Xàtiva o la de Morella (Iradiel, 1989: 268; Furió, 1995: 186; López, 1986: 1636-1644). Una marcada diferència poblacional respecte aquestes ciutats que explica que Alzira sempre es localitze per sota d'aquestes en la documentació referent als parlaments o actes de Corts i que tot i ser una vila destacada dins del braç reial, únicament va aportar - com la resta de viles de reialenc - un síndic a les Corts de Martí l'humà, front als dos representats de les ciutats de Xàtiva i Morella i els quatre representats de la capital (Muñoz, 2004: 103). A més a més del seu volum demogràfic, l'adquisició de privilegis i franqueses reials atorgaren a la vila certa singularitat política, mentre que el seu gran dinamisme socioeconòmic li va permetre esdevindré en un autèntic centre del mercat rural comarcal (Martínez, 2012). ${ }^{2}$ Tot plegat, la consideració d'aquests trets permeten identificar a dita vila com un nucli fonamental en l'estructuració del territori comprés entre la capital de regne i la ciutat de Xàtiva, el que alhora s'insereix en un procés més ampli d'articulació de la xarxa urbana de la corona (Garcia-Oliver, 2012: 153-168). 
A nivell d'organització política i institucional, la incertesa en quan al ritme i la cronologia d'introducció de les magistratures locals a la vila quedà resolta a partir de 1278 , any en què Pere III atorgava a les principals viles de reialenc -és a dir a Morvedre, Xàtiva, Alzira i Gandia - idèntica organització municipal que la conferida per Jaume I a la ciutat de València en $1245 .{ }^{3}$ Des d'aleshores, l'universitas alzirenya va comptar amb una sèrie d'institucions polítiques locals ben definides, que assumien en diferent grau els quefers derivats del regiment i l'administració sociopolítica i econòmica de la vila. ${ }^{4}$

A grans trets, aquesta organització municipal comptava amb un executiu de govern constituït per quatre jurats que alhora eren assessorats per un consell particular, format per unes vint-i-cinc persones que constituïen un organisme deliberatiu. Tanmateix, en assumptes de gran importància per a la vila es reunia el consell general format aproximadament per vint o trenta persones més, en el que s'enquadraven tant prohoms importants de la vila així com, en menor mesura, representants dels dos ravals - el de Santa Maria i Sant Agostí- i dels llocs existents en la seua contribució general (Furió i Garcia-Oliver, 1985: 1611-1634). Junt aquests la màxima autoritat en matèria civil i criminal hi era el justícia, qui gaudia de mer i mix imperi. Al mateix temps, la presència reial a la vila era assumida per un batle local, representant del rei i dels interessos del patrimoni reial en la vila. ${ }^{5}$ Per sota d'aquest quadre sociopolític municipal, estava el mostassaf amb competències en matèria econòmica $i$ de regulació del mercat, el síndic amb funcions de representant o procurador del municipi i l'escrivà municipal, encarregat de conferir i donar fe pública de les ordenances. Encara per sota d'aquests, es va anar desenvolupant un entramat d'oficials inferiors (lloctinents de cada magistratura i ofici, missatgers, escrivans, agutzils) en sincronia amb les necessitats derivades del propi desenvolupament de l'administració local.

Pel que fa al nombre, al sistema de renovació de càrrecs, a l'extracció social, la vigència $i$ les atribucions de cadascuna de les magistratures $i$ oficis han estat ben estudiades per a les ciutats de la Corona d'Aragó, destacant el monogràfic de la revista Estudis Baleàrics dedicat al «Règim municipal a la Corona d’Aragó» (Barceló, 1988). Per la seua part, els estudis al voltant del govern

3 Privilegi núm. 2 de Pere III, atorgat a Lleida el 8 de setembre de 1278 (Alanya, 1515:117).

4 Al voltant de la concessió del ius estatuendi, és a dir de la capacitat legislativa de l'executiu de govern, als magistrats valencians a partir de 1283 (Furió i García-Oliver, 2007: 22).

5 Al voltant de la batlia local d'Alzira i la resta de batlies de la Ribera al segle XV (Furió, 1986: 784 940). 
municipal al regne de València han privilegiat la pròpia capital, des de la tesi d'Ignacio Villalonga Villalba (1916) fins a les investigacions desenvolupades per Ernest Belenguer Cebrià (1976) i Rafael Narbona Vizcaíno (1991). A la resta del territori regnícola, es compta amb els estudis de José Antoni Barrio Barrio per als casos de les ciutats d'Alacant i d'Oriola (1988; 2002), amb els d'Emilia Mollà Ribes per a la ciutat de Xàtiva (1987) així com els de Carlos Fradejas i Piedad García per a la vila d'Onda (1989), finalment Pau Viciano ha abordat l'estudi de la vila de Castelló (2008). Des d'aquesta perspectiva, s'evidència com encara hi manquen molts estudis al voltant del funcionament intern de les institucions de govern de la major part de les grans viles del regne com Morella, Sagunt (Morvedre), Cullera, Gandia, Borriana, Dénia, Llíria, Vila-real, Alpont o Alcoi.

Amb tot, la historiografia existent coincideix en assenyalar com pertot arreu del territori les magistratures eren renovaves anualment mitjançant un sistema organitzat per a la provisió de càrrecs, que va sofrir diverses modificacions al llarg dels segles XIV i XV. En aquest sentit, l'evolució del sistema electoral es va desenvolupar des de la primitiva designació directa o cooptació per part dels dirigents locals a la intervenció reial amb la implantació de la insaculació des de mitjans del Quatre-cents gairebé en quasi totes les ciutats i viles de la corona. Junt aquestes dinàmiques en la renovació de les magistratures s'assenyala com un fenomen - també generalitzat - el control d'aquestes magistratures per part d'una oligarquia que va aconseguir perpetuar-se al capdavant de les institucions municipals. L'origen d'aquesta oligarquia deu relacionar-se amb la pròpia adquisició d'autonomia jurisdiccional i administrativa per part de la comunitat local en la mesura que aquesta va contribuir a distingir al grup dirigent de la resta de la comunitat en qualitat de prohoms (Narbona, 2007a: 351- 396; 2007b, 121-122).

Davant d'aquest context general, la vila d'Alzira no representa un cas excepcional sinó que també va seguir durant els segles baixmedievals les mateixes dinàmiques sociopolítiques. Malgrat però, tot i que a grans trets es coneix el funcionament del sistema electoral i que és una vila de cavallers i de notaris, s'ha anat posposant inexplicablement un estudi bàsic com és la identificació de les famílies que constituïren el nucli de poder local alzireny al segle XV. ${ }^{6}$

6 Les modificacions dels sistema electoral alzireny han estat recollides en part (Parra, 1984; Lairón, 2001: 14-15). Per altra part, al voltant de la composició social i l'arrelament de les famílies existents a la vila d'Alzira als segles baixmedievals (Furió, 1986: 78-83). 
En aquest sentit, observar el ritme de les modificacions del sistema electoral en la vila i identificar la seua elit dirigent al Quatre-cents és un dels objectius d'aquest estudi. Al mateix temps, es pretén contribuir a fixar les particularitats, ritmes i cronologies d'evolució pròpies respecte al conjunt dels estudis d'història sociopolítica i institucional de la Corona d'Aragó des de l'observatori privilegiat d'una de les viles més importants del regne de València.

D'acord amb aquest objectiu, la metodologia emprada s'ha centrat en la identificació d'aquelles famílies i individus que desenvoluparen amb major frequiència les magistratures del justícia, jurat i mostassaf, així com els càrrecs de consellers, síndic i escrivà municipal a partir de la lectura exhaustiva dels Llibres d Actes dels Jurats e del Consell, conservats a l'Arxiu Municipal d'Alzira, durant el període comprés entre 1388 i 1500 . Aquests llibres d'actes municipals, permeten realitzar un treball sistemàtic dels detenidors dels càrrecs, tot i presentar llacunes documentals corresponents a vint-i-quatre exercicis anuals entre la fi del segle XIV i inicis del segle XV. ${ }^{7}$

Tot plegat, l'estudi es divideix en dues parts: una primera en la que s'aborda la successió dels diferents mètodes d'elecció i una segona en la que s'analitza l'ocupació efectiva de les elits locals en les principals magistratures i càrrecs municipals. Finalment, es realitza una sèrie de consideracions al voltant d'alguns dels individus i dels llinatges que formaren part del grup dirigent de la vila al llarg del període.

\section{L' evolució del sistema d'elecció dels càrrecs municipals}

\subsection{La cooptació}

Desconeixem al detall el sistema de regulació dels càrrecs públics municipals implantat immediatament desprès de la conquesta de la vila tot i que segurament hi devia ser alguna modalitat del sistema de cooptació, tal i com era vigent a la ciutat de València. ${ }^{8}$ Aquest mètode d'elecció es basava en la desig-

7 Les llacunes documentals corresponen als exercicis anuals iniciats en 1389, 1391, 1392, 1393, 1395, $1400,1403,1406,1408,1409$, 1414, 1415, 1416, 1417, 1418, 1419, 1420, 1421, 1427, 1436, 1442, $1461,1480,1499$. Tot i que en alguns casos poden ser compensades a partir de la lectura de les actes conservades al fer referència aquestes als anys precedents.

8 Aquest mètode fou introduït per primera vegada a la ciutat de València en 1245 on va perdurar fins el privilegi de Pere III en 1283. A Mallorca i a Barcelona la cooptació fou introduïda en 1249 i perduraria fins a 1373 i 1479, respectivament. Per tota la geografia de la Corona, aquesta arbitraria designació va 
nació directa per part dels magistrats que deixaven el càrrec dels seus predecessors, qui conjuntament amb els primers elegiren el seu consell particular (Santamaria, 1981: 291-364). Per altra part, tot i que aquest mètode de cooptació va ser substituït a la ciutat de València pel sistema de redolins en 1283, aquesta substitució en el cas d'Alzira únicament va afectar a les magistratures (jurats, justícia i mostassaf), de forma que en l'elecció dels càrrecs menors la designació directa per part dels magistrats va continuar vigent fins a 1432 . Doncs, les actes municipals mostren com encara a les altures de 1426, any en què Xàtiva rebia el privilegi d'insaculació (Barrio, 1992: 499-503) i a la ciutat de València s'introduïa el sistema de la ceda reial (Narbona, 1991: 48-52), l'elecció dels consellers a la vila es feia de forma que los dits honorables jurats ab los elets en lo present any feren e ordenen en consellers dels dits honorables jurats novells los honorables vehins $i$ habitadors de dita vila infrasegüents. ${ }^{9}$ Tot plegat, el fet que no s'aplique el mètode de redolins instaurat en 1283 per Pere el Gran al càrrec de conseller evidència que fins al primer terç del segle XV el seu desenvolupament estava sota estricte control d'una elit dirigent consolidada. Aquesta elit exerciria hegemònicament el seu poder ocupant les altes magistratures i cooptant els càrrecs del consellers en benefici propi fins a 1432. Això significa que fins aquesta última data, formar part o promocionar de grau dins de la societat política alzirenya depenia de la capacitat dels individus o de les seues famílies d'establir nexes d'unió amb els principals membres de l'oligarquia.

En aquest sentit, la manca de documentació relativa al segle XIII i primera part del segle XIV no permet una aproximació a les famílies que aconseguirien reproduir-se en el govern municipal. Així com tampoc les dades fragmentàries relatives a la segona meitat del segle XIV permeten un estudi en profunditat, tot i que Aureliano Lairón va enunciar com entre les famílies més poderoses de la vila deurien estar els Serra, els Eximénez de Tolsana, els Roca, els Destorrents, els Galindo, els Safàbrega, els Cercós, els Boquet, els Martorell, els Enyech d'Arándiga, els Carcassona, els Fuster, els Costeia, els Llorenç i els Castelló (Lairón, 2001: 13). Certament, queda constatat que així

permetre la perpetuació en les magistratures d'un escàs nombre de llinatges ciutadans, vinculats entre si per aliances matrimonials i polítiques així com per una xarxa de solidaritats mútues. En aquest sentit, la historiografia ha identificat com a famílies patrícies que monopolitzaren les altes magistratures de les ciutats els Descatlar i Llucmajor a Mallorca, els Torró i Destorrent de Barcelona i els Suau i els Marrades a València (Narbona, 1996: 202-217). 
seria almenys en els casos dels Serra, els Martorell i els Safàbrega tres de les cinc famílies que desenvoluparen un nombre major de càrrecs municipals a la vila al segle XV com veurem més endavant. També es confirma en el cas d'un prohom singular com fou Bartomeu Enyech d'Aràndiga, doncs aquest cavaller va ser síndic de la vila durant les Corts convocades per Martí l'Humà, on va tindre un paper destacat (Muñoz, 2004: 747-789). ${ }^{10}$

\subsection{El mètode de redolins (1283-1432)}

Per altra part, com hem dit anteriorment, el mètode de redolins si va ser instaurat a la vila a partir de 1283 en el cas de les eleccions de les tres magistratures, on va perdurar fins a 1432. Durant la vigència d'aquest mètode els jurats i el consell elegien a sis prohoms o electors per cadascuna de les dues parròquies - la de Santa Maria i la Sant Agostí- que alhora elegien lliurement els seus candidats per a desenvolupar el càrrec (a raó de sis candidats per cada parròquia). Així mateix, es seguia el procediment habitual, cadascun dels noms d'aquests candidats eren escrits en un tros de pergamí que es plegava i era recobert de cera formant un redolí. Els diversos redolins eren submergits en un recipient d'aigua i mitjançant la intervenció d'un xiquet s'extreien quatre redolins i amb ells els nous jurats, sent nombrats directament pel batle o pel seu lloctinent. Mentre que en el cas de l'elecció del justícia eren extrets tres redolins entre els quals el batle local elegia un, igualment ocorria en el cas de l'elecció del mostassaf. Per tant en aquests dos darrers càrrecs hi havia que superar no sols el sorteig sinó, a més a més, gaudir del beneplàcit del representant del rei a la vila.

Aquest nou mètode de provisió de les altes magistratures municipals va garantir una major participació veïnal. Tot i que el fet de tenir que elegir sis electors de cadascuna de les dues parròquies i aquests a la seua vegada a candidats va precipitar ja a finals del segle XIV un clima de desconfiances mútues, que va enfrontar segurament els membres més destacats de la vila. ${ }^{11}$ Prova

10 Per la seua part, dintre de l'administració municipal Bartomeu Enyech d'Aràndiga va desenvolupar almenys la magistratura de jurat en 1373, 1387, 1395, 1399, 1404, la de justícia en 1384 i va ser conseller en diverses ocasions $(1362,1388,1397,1398,1401,1402$ i 1403) coincidents amb el seu desenvolupament com a síndic de la vila en les Corts. És possible que exerciria un major nombre de càrrecs públics difícils d'identificar però a causa que la seua cronologia vital coincideix amb la de majors buits documentals.

11 De fet es documenta com en l'elecció del mostassaf de 1388 els elegidors de la parròquia de Santa Maria, no es posaven d'acord en els seus candidats. La discòrdia residia en incloure o no a Francesc Torrent, sent partidaris de metre'l dos elegidors mentre que quatre d'ells deien que aquest no es podia introduir en el bací d'aigua per certes raons, sent partidaris d'incloure en el seu lloc a Antoni Safà- 
d'aquestes tensions foren els pledejos esdevinguts en 1388 entre individus destacats de la vila contra aquesta per motius de les eleccions. La importància de dits pledejos va motivar a l'executiu de govern a establir que aquell qui en el moment previ de qualsevol elecció estigués pledejant contra la vila tenia l'accés vedat a dita elecció. Ara bé, es contemplava la possibilitat de poder ser introduït immediatament en les eleccions si es renunciava al plet contra la vila. Aquesta restricció d'accés a les magistratures i càrrecs intentava dissuadir a certs singulars (Pere Serra, en Jaume Serra, Joan Serra i Jaume Martorell entre d'altres prohoms) en defensa dels quals Bernat Costeia argumentava que aquests no pledejaven contra la vila sinó que defenien els furs i privilegis, per tant no devien ser exclosos..$^{12} \mathrm{El}$ malestar es va incrementar fins al punt que el consell general va endurir la restricció d'accés als oficis de la vila, proveint que quant elecció de justícia, de jurats e de mustaçaf se haurà a fer, que y sia tenguda aytal forma: que aquell o aquells qui pledejen de present, o pledejaran d'aquí a avant, ab la dita universitat per qualsevulla rahó, ne lurs procurador o procuradors, ne advocats ne alcun altre qui a aquells do consell, favor ne ajuda en les dites qüestions, que aquests aytals no sien jamés mesos en alcun dels dits oficis, ne en elegidós de alcun dels dits oficis, ans de tot en tot ne sien remoguts e foragitats de tot ofici e benefici de la dita vila, e que si alcuns d'aquells eren meses per inadvertència vel alias en elegidós dels dits oficis o en alcú d'aquells, e encara en los dits oficis o alcú de aquells, que aytal elecció fos e romangués de sí nul $\cdot l a .^{13}$

A efectes pràctics, aquesta restricció suposava que tots aquells notaris que procuraren contra la vila, és a dir contra els interessos dels dirigents d'aquell any, no podrien desenvolupar càrrecs públics. De fet, una de les principals

brega. Davant d'aquesta disjuntiva, el consell general va decidir que fora valida l'opció dels quatre concordes, sent curiosament Bernat Safàbrega, notari, un dels elegidors de la parròquia de Santa Maria, qui va protestar la decisió argumentant que dita elecció no s'havia realitzat seguint els furs. Malgrat la seua protesta, l'elecció s'efectua igualment. AMA, Llibres dels Actes dels Jurats e Consell, 03/1, ff. $14 \mathrm{r}-15 \mathrm{r}$.

12 Aquesta mesura es contextualitza en un ambient de confrontació entre la vila i alguns prohoms d'aquesta sota la procuració de Bernat Costeia, notari, jove, per raó de les eleccions del justícia i la dels jurats, en el qual estava immers fins i tot el batle local Ramon Samorera. La problemàtica vers l'elecció del justícia queda clara, doncs Lop Eximénez de Perencisa fou nomenat justícia de la vila en desembre de 1387 per manament reial per motius que desconeixem, prescindint dels mecanismes de les eleccions municipals. Més difícil resulta indagar en la problemàtica suscitada en l'elecció dels jurats, ja què no es conserven les actes municipals, únicament podem observar que els jurats elets foren Gonçalbo López de Pomar, Blasco d'Osca, Nicolau Castelló i el notari Bernat Llorenç. AMA, Llibres dels Actes dels Jurats e Consell, 03/1, ff. $14 \mathrm{r}-15 \mathrm{r}$.

13 AMA, Ibídem, 03/1, ff. 15r- 16v. 
consequiències greus d'aquell mateix any seria que la majoria de notaris de la vila hi eren impedits, per tant l'elecció de l'escrivà de la sala del 6 de juny de 1389 no es podia realitzar per ço com molts notaris hi ha qui són dels singulars que pledej[en] ab la universitat e de la part de aquells, los quals notaris poden caure en lo [d] it ofici. Davant d'aquesta situació, els jurats designaren directament a Bernat Falcó com a regent de l'escrivania municipal, un home de confiança qui havia estat majordorm (clavari) en la passada juraderia. ${ }^{14} \mathrm{~A}$ partir de juny de 1397, es va restringir la participació en la vida política local als deutors de la vila. Gairebé un any més tard, entrava en vigor altra regulació relativa en aquest cas al parentesc, en concret es prohibia que pare i fill, sogre i gendre, i dos o tres germans o més foren nomenats al mateix temps per a l'elecció del justícia, jurats, mostassaf o altres oficis de la vila. ${ }^{15}$ Finalment, en 1401 es matisava la restricció a les eleccions als nouvinguts, als quals se'ls havia marginat del govern de la vila fins que no hagueren viscut en ella almenys durant una dècada. En aquest sentit, l'elit dirigent estava conforme aleshores en fer partícips del regiment de la vila a tot aquell veí nouvingut que disposarà d'un patrimoni de 500 lliures, és a dir 10.000 sous (Lairón, 2001: 137). Aquesta mesura, permet observar com l'arrelament a la vila i gaudir d'un alt nivell socioeconòmic eren dues condicions intrínseques al propi desenvolupament dels oficis municipals.

En aquest context de proliferació de la normativa d'accés a les eleccions, una anàlisi dels càrrecs permet observar com en conjunt durant el període 1388 fins a 1432 en destaquen cinc famílies en el desenvolupament de les principals magistratures. En aquest sentit, els llinatges Martorell, els Gombau, els Serra, els Vendrell i els Safàbrega van predominar al capdavant de l'executiu de govern, acumulant entre nou i vuit càrrecs cadascun. En les magistratures del justícia i mostassaf, on els buits documentals per aquest període són més acusats, l'accés va ser més restringit en tant que ocupava el càrrec

14 AMA, Ibídem,03/1, f. 92r.

15 En aquest sentit, el consell general de la vila proveí el 26 de juny de 1397 que aquell qui abans de l'elecció dels jurats no hagués efectuat el pagament de la peita de l'any seria impedit. En conseqüència, s'establí l'obligació del peiter que abans d'aquesta data donarà compte dels veïns deutors del principal impost municipal. AMA, Ibídem, 03/4, ff. 8r -10r. Per altra part, el 13 de juny 1388, el rei Joan I concedia un privilegi que establia la prohibició que pare i fill, sogre i gendre, i dos o tres germans o més foren nomenats al mateix temps per a elecció de justícia, jurats, mostassaf o altres oficis de la vila, establint una pena de 2000 florins (Lairón, 2001: 86-87). La vila d'Alzira es fa resolt d'aquest privilegi en el consell de 28 de setembre de 1398, convocat amb motiu de l'elecció de mostassaf, en el qual s'exposa que dita restricció afectava únicament aquell any als fills del notari Pere Serra (Mateu, Joan, Arnau i Bartomeu), AMA, Llibres dels Actes dels Jurats e Consell, 03/5, ff. 30r -32r. 
anual una única persona, tot i que s'adverteix la presència en el justiciat en diverses ocasions dels Martorell, els Gombau i els Serra. Mentre que únicament aquesta última família de les cinc famílies esmentades es documenta en el càrrec del mostassaf. A més a més, Miquel Vendrell entre 1396 i 1416 i Antoni de Martorell entre 1417 i 1428 van exercir de batles locals de la vila. ${ }^{16}$ Per tant, la coincidència d'aquestes cinc famílies en l'executiu de govern junt a la seua presència a les altres dues magistratures evidència la seua preeminència al capdavant del govern municipal i, al capdavall, les identifica com els llinatges més poderosos alhora de designar els consellers i altres càrrecs mitjançant el sistema de cooptació.

\subsection{La introducció del sistema de sacs (1432-1446)}

La conflictivitat sociopolítica, possiblement pel xoc d'interessos entre algunes d'aquestes famílies, junt a la implicació del poder reial en la recerca de solucions, va motivar que entre finals del segle XIV i inicis de Quatre-cents s'accentuarà la intervenció reial en el govern de la vila. Així en abril de 1427, les desavinences en les anteriors eleccions dels jurats i del mostassaf van provocar que el consell ordenarà que aquestes foren fetes des d'aleshores i per un termini de set anys pel mètode dels sacs. Malgrat però, aquest intent fallit del consell - ja que no va arribar a aplicar-se - va culminar però en 1432 amb la introducció per iniciativa reial d'un nou sistema de provisió de càrrecs segons la forma practicada a Xàtiva. ${ }^{17}$ En aquesta ciutat s'havia introduït en 1427 la insaculació, un nou sistema d'eleccions de magistratures i càrrecs municipals que pretenia acabar amb l'excessiu control oligàrquic de les institucions municipals (Barrio, 1992: 499-503). En un mateix sentit, com s'ha dit anteriorment, en la ciutat de València un any abans s'havia introduït la ceda reial que confeccionada pel rei o pel racional, incloïa el noms dels candidats que participarien en el posterior sorteig.

En aquest marc general d'intromissió regia en les eleccions municipals, el consell general de la vila a pesar de l'oposició de certs sectors accepta fer eleccions amb el nou sistema de renovació de càrrecs durant un termini de deu anys. Així mateix, les actes municipals conservades mostren com al consell general de la vila reunit el 13 d'abril de 1432 es va presentar Pere Feliu, conse-

16 Veure en aquest estudi taula I, II, III, IV, V i VI.

17 AMA, Llibres dels Actes dels Jurats e Consell, 03/20, ff. 34v; 42v; 45r-46r. 
ller del rei, qui amb una carta de creença reial va comunicar la voluntat d'Alfons el Magnànim que els prohoms de la vila votaren en aquell consell si acceptaven o no la forma d'eleccions practicada a Xàtiva. Això significava que devien decidir si acceptaven o no realitzar les eleccions dels oficis de justícia, jurats i mostassaf, consellers i altres oficis de la vila a partir de redolins introduïts en sacs. Davant aquest requeriment, el consell general es va dividir entre partidaris d'aplicar el nou sistema i els contraris a fer-ho. Els primers en majoria signaren sindicat en el notari Innocenci de Moya, a qui atorgaren ple poder per a negociar amb el rei. ${ }^{18}$ En contrapartida, es negaren a signar aquell sindicant el justícia Jaume Navarro, tres dels quatre jurats (aleshores constituïen l'executiu de govern Pere López de Pomar, Simó Sanç, Alfons Falcó i Pere Gilabert), el síndic de la vila i altres prohoms que consideraven que allò que se'ls requeria contradeia els furs i privilegis dels regne. ${ }^{19}$ Deu dies després, sota el malestar evident de certs membres del consell, es va tornar a presentar personalment Pere Feliu a la vila i junt a Bernat Guillem Saburgada, secretari de la reina, i Bernat Roig, notari, va elaborar una relació de les persones que ben vist li fou per a formar oficials. Així doncs, després de revocar els càrrecs existents es va procedir a l'elecció dels nous mitjançant els sacs..$^{20}$

Junt aquest canvi del sistema electoral van entrar en vigor noves restriccions que regulaven l'accés als oficis, establint com a requisit imprescindible per a ser inclòs en els sacs de les eleccions estar casat i tenir casa i habitació dins de la vila. ${ }^{21}$ Amb aquesta mesura, es vetava el desenvolupament de càrrecs públics als veïns de la vila que vivien en els llocs de la seua contribució, el que farà créixer el malestar entre aquells. En general, l'entrada o no en el sac de les eleccions va ser la qüestió que més controvèrsies va provocar. El propi rei va autoritzar en abril de 1438 que foren introduïts al sac de les eleccions dels jurats els redolins de Lluc de Martorell, Bartomeu Garrigues i de Joan Alcanyís, però es va veure obligat a rectificar el 7 de maig d'aquell mateix any. A raó d'aquesta provisió reial es documenta l'acta municipal del 15 de juny en la qual s'efectua l'extracció d'aquests i en la que s'esmenta que al

18 Innocenci de Moya va desenvolupar el càrrec d'escrivà de la sala entre 1397 i 1413, després d'haver obtingut la seua carta de notaria per manament reial en 1394. Entre els anys 1413 i 1426 es va traslladar a la ciutat València, i des de la capital es va convertir en el principal ambaixador de la vila en tant que va exercir com a síndic per aquella en les Corts convocades per Alfons el Magnànim entre 1428 i 1446.

19 AMA, Llibres dels Actes dels Jurats e Consell, 03/24, ff. 62r-67r. Aquesta introducció del sistema de sac i la problemàtica entorn a ella va ser recollida per José Maria PARRA (1984: 362-364).

20 AMA, Llibres dels Actes dels Jurats e Consell, 03/26, ff. 36r- 37r.

21 AMA, Ibídem, 03/23, ff. 56v-58r. 
sac dels jurats hi havia vint-i-sis redolins, quedant-ne vint-i-un després d'haver llevat aquests i també els dels ja difunts Antoni de Martorell i Pere Goçalbo. ${ }^{22}$

\subsection{La insaculació (1446 -1466)}

Passades dues dècades, el sistema de sacs - que en la pràctica no havia suposat més que un assaig de la insaculació- havia garantit una major circulació dels individus en les magistratures, tot i que no havia aconseguit acabar amb les disputes polítiques. Causa que junt al incompliment dels «capítols del Sac» exigiren una normativa més estricta del sistema d'eleccions, que es va aconseguir mitjançant la concessió reial del privilegi d'insaculació el 13 de juliol de 1446. Aquesta es produïa en un context on la insaculació ja havia estat instaurada a Xàtiva en 1427, a Menorca en 1429 (Serra, 1970: 305-329), a Saragossa en 1442 i on sols una dècada més tard ja es practicava a totes les viles aragoneses (Aranda, 2003: 54-55; Falcón, 1988: 73-91). A la vila d'Alzira, la insaculació s'instaurava amb caràcter temporal, doncs s'establia una vigència d'una dècada durant la qual els prohoms accedirien a les eleccions a partir de deu sacs per a un total de tres magistratures (justícia, jurat i mostassaf) i tres càrrecs (consellers, escrivà de la sala i síndic). La gran diferenciació es va produir entre els homes de paratge i els homes de vila, en tant que els primers foren introduits en una capsa anomenada capsa del justícia, jurats, mostassaf $i$ consellers de homes generosos. En aquesta serien introduits tots els homes de paratge de la vila que habitaren en ella i que acreditaren tenir 6.000 sous. Igual quantitat que devien acreditar els homes de vila per a ser introduïts en la capça de justícia, capsa de jurat en cap així com en la capsa de mostassaf. Mentre que en 4.000 sous es va xifrar la quantitat per a poder ser introduït en la capsa de jurat segon d'homes de la vila i la de jurat terç $i$ quart. En quant a la capsa de consellers majors aquesta contenia tots els noms que hi formen part de les capces anteriorment citades d'homes de vila. Per altra part, respecte a la capsa de consellers menors únicament s'indica que són introduïts els noms de les persones hàbils i suficients a dit ofici, únic requisit a part del de ser notari que sofrien la capsa dels escrivans i la capsa dels síndics. ${ }^{23}$

22 AMA, Ibídem, 03/30, ff. 13r-15r.

23 AMA, Còdex especials, 00/4, ff. 177r-193v, corresponents als capítols del Regiment dels oficis de la insigne vila d'Algezira. Aquests capítols, que foren copiats per l'escrivà municipal l'1 de maig de 1471 - coincidint en el restabliment del sistema d'insaculació - han estat publicats en part per Aureliano Lairón (2001: 159-183). El fet que dit autor no publicarà els folis següents a dits capítols -els quals 
Per altra part, aquestes disposicions que definien la insaculació foren previstos d'una regulació més específica que afectava tant a les pròpies magistratures i oficis com als individus introduïts en les capses de les eleccions. En aquest sentit, pel que fa a la regulació interna de les magistratures i oficis, es va prohibir que un individu ocuparà un mateix càrrec de forma consecutiva, alhora que tampoc es permetia el desenvolupament de dos càrrecs al mateix temps. Així mateix, s'impedia que coincidiren pare i fill, sogre i gendre i germans un sent justícia i altre jurat en cap en un mateix any, a més es recolliren les causes d'impediments vigents a la vila fins el moment $i$ ja esmentades anteriorment. Per altra part, es va disposar que les capses s'obriren cada dos anys per a poder introduir nous noms en elles o bé per a què els que ja estaven pogueren promocionar de grau. Ara bé, per garantir que no es pervertex-se l'ordre de la rahó quant alguns volen esser feyt ans mestres que dexembles s'establí que en l'admissió i promoció de graus es seguirà un ordre progressiu. D'aquesta forma, aquell que volgués ser col·locat en la capsa de jurat primer obligatòriament devia ser col-locat primer en la capça de jurat tercer i quart, podent ser admès únicament una persona per any. ${ }^{24}$ Transcorreguda la dècada de vigència d'aquests capítols, la vila va acordar mantenir aquest sistema d'elecció en tant que no contradeia cap manament reial. Malgrat però, l'escalada de tensions i certs interessos personals que la documentació municipal no permet conèixer van propiciar que tres dels quatre jurats de l'exercici polític 1465-1466 (Francesc Martí, Galceran Gombau, major, Joan Gombau, notari, Onofre Tamarit) sense consultar al consell suplicaren a Joan II la revocació del sistema d'insaculació, que es va efectuar el 13 de maig de $1466 .{ }^{25}$

\subsection{La ceda reial $(1466-1468)$}

El 24 de maig següent, coincidint amb el dia de les eleccions de la juraderia, els jurats presenten a la vila la nova provisió reial mitjançant la qual es

\footnotetext{
són tractats en aquest estudi com una continuació dels propis capítols en tant que es conserva un llistat sistemàtic de les persones que ocuparen els càrrecs de justícia, jurat, mostassaf, síndic i escrivà municipal entre el període 1446 i 1516, la introducció de la ceda reial l'any 1466 i el posterior restabliment de la insaculació - que explica la pròpia recopilació aleshores dels capítols - junt amb les persones que foren introduïdes en les noves capces de 1469- justifica que emprem en les nostres referències la font documental original. Una font que per altra part presenta una doble foliació, que explica que mentre Aureliano ha emprat l'original de 1'escrivà, en aquest estudi s'ha optat per la foliació realitzada posteriorment.

24 Cf. AMA, Còdex especials, 00/4, ff. 188r -188v.

25 Cf. AMA, Llibres dels Actes dels Jurats e Consell, 03/56, f. 96r. C.f (Parra, 1986: 375-176).
} 
comunicava la revocació del sistema anterior alhora que s'introduïa una nova fórmula de provisió dels càrrecs, segons la forma de fur del regne de València i de les ordenances de la ciutat homònima. Al mateix temps, s'introduïa a la vila un nou requisit per a ser inclòs en les eleccions com era el fet de tindre un cavall de valor de tres-cents sous, comprat anteriorment o bé en el transcurs dels tres mesos a partir de la data de la concessió del privilegi. ${ }^{26}$

Doncs, en la capital estava vigent, com hem dit anteriorment, al voltant de 1426 el sistema de ceda reial, en el qual el rei o el racional confeccionaven un llistat amb els noms de les persones per al seu posterior sorteig (Narbona, 1995: 48). En el cas de la vila d'Alzira, Joan II disposa específicament que les vuit persones o consellers restants de l'última elecció dels jurats juntament amb els jurats que havien acabat la seua juraderia seleccionaren anualment a dotze candidats per al càrrec de jurat o per a altres càrrecs. Els noms d'aquests dotze seleccionats devien ser escrits en una llista que devia ser supervisada pel rei o el batle local. En la pràctica, aquell 24 de maig de 1466 es reuniren els jurats, el batle local i el justícia durant tot el dia i fins sonades les onze ores de la nit e corrent les dotze per realitzar dita selecció de candidats, demora de temps que denota l'existència d'interessos enfrontats. Aquestes mateixes dificultats van impedir al setembre següent la confecció del llistat dels dotze candidats per a l'elecció del mostassaf, fet que va motivar que el batle comunicarà al rei la incidència i aquest, prèvia suplica d'Olfo de Próxida, decidirà nomenar mostassaf de la vila a Onofre Tamarit. ${ }^{27}$

Amb tot, la introducció d'aquest nou sistema i les complicacions a l'hora de confeccionar els llistats dels candidats va provocar la protesta reiterada de la major part dels prohoms del consell, partidaris de retornar als capítols del regiment del sac, expressió que feia referència aleshores al sistema d'insaculació. En aquest sentit, al·legant la necessitat de canviar el sistema d'eleccions per les grans despeses que suposa per a la vila i encara més per resecar les grans passions que eren entre los dits vehins de la vila d'Algezira

26 Cf. AMA, Ibídem, 03/56, f. 96r . També a José Maria Parra (1986: 375 -176).

27 AMA, Còdex especials, 00/4, ff. 199r -200r. Aquesta intermediació reial no va ser l'única, doncs en l'elecció del justícia en desembre 1467, el notari Joan Tolosa presentà una provisió reial que li assegurava ser nomenat justícia, en el supòsit que un dels tres redolins extrets en el sorteig contenia el seu nom. I així va ocórrer, fet que mostra com a la vila certs individus que podem considerar l'elit emergent gaudien del favor reial. De fet Joan Tolosa feia pocs anys que desenvolupava càrrecs en el govern municipal. En aquest marc, l'elecció dels jurats mitjançant la ceda reial va anar acompanyada per la elecció directa d'aquests de l'escrivà de la sala, qui fou elet Joan Piquer, sense la participació del consell. AMA, Ibídem, 00/4, ff. 200r -201r. 
i els habitadors de aquella, en desembre de 1468 el consell general de la vila va decidir enviar missatgers a Saragossa per a suplicar al rei el retorn al sistema insaculatori. ${ }^{28}$

\subsection{El restabliment de la insaculació en 1469}

Joan II, al context de la guerra civil catalana (1462-1472), va aprofitar les supliques dels missatgers alzirenyes per practicar, com era sovint, les formules pactistes. De forma que el rei concedia a vint anys la insaculació a la vila a canvi que aquesta li concedirà un donatiu de tres-cents timbres. Quantitat que suposa l'endeutament de la vila $i$, en aquest cas, la lògica recurrència al carregament de censals va anar acompanyada d'una mesura extraordinària que afectava a les institucions de govern per per garantir les represàlies cap als qui han fet, procurat o ginyat, o tractat lo dit toliment de capítols del dit regiment de sach. Doncs, des d'aleshores i fins que foren quitats els carregaments una part del salari pertanyent a les magistratures i oficis serien transferits al pagament de les pensions i al quitament dels censals. ${ }^{29}$ Per altra part, una vegada restablert el sistema insaculatori, es va precisar de la presència del batle general i de l'advocat de la ciutat de València per a la constitució de les noves capces. ${ }^{30}$

\section{L'accés i el desenvolupament efectiu de les magistratures i principals càrrecs municipals}

Observades les modificacions del sistema electoral, cal considerar - com s'ha enunciat en pàgines anteriors - que serien els individus i les famílies amb major capacitat econòmica les que accedirien a l'administració municipal. Doncs, tots els oficis municipals identificats per Antoni Furió en les fonts

28 AMA, Ibídem, 00/4, f. 201v.

29 La distribució dels descomptes del salari no es va fer proporcionalment ni atenent a la seua responsabilitat dintre del govern, doncs la distribució dels pagaments fins que es fera quitament del censals seria de 150 sous del salari anual de l'escrivà de la sala, 100 sous del salari del justícia i cadascun dels quatre jurats, 50 sous per part dels salari del mostassaf i del l'organista i 40 sous de l'estipendi del síndic (Parra, 1986: 380-382). AMA, Llibres dels Actes dels Jurats e Consell, 03/58, ff. 127v, 129v i 135v.

30 El nombre de persones i el llistat de noms dels quals foren inclosos en cadascuna de les noves capses es conserven amb incorporacions dels anys posteriors - indicant l'ascens de grau per part de certes persones - així com notes al marge indicant el desaveïnament o la defunció d'un persona: AMA, Còdex especials, 00/4, ff. 203r-207r. 
fiscals alzirenyes superen el nivell de riquesa, que dit autor estableix en un patrimoni igual o superior a les 100 lliures (2.000 sous). Segons les seues dades, en $1399 \mathrm{amb}$ aquest patrimoni hi havia a la vila setanta-set individus, que representaven el 12,6\% del total dels contribuents de la peita que acumulaven per altra part el 47,5\% de la riquesa de la vila. Això significa que l'accés als càrrecs polítics de la vila estava restringit a un selecte grup de famílies enriquides. En 1467, en una conjuntura de davallada demogràfica a la vila, el percentatge de les famílies que superaven el llindar de les cent lliures s'havia incrementat fins el $21 \% \mathrm{i}$ en conjunt aquestes atresoraven ja el $65 \%$ de la riquesa de la vila (Furió, 1986: 706-707). Ara bé, aquesta tendència d'enriquiment de la minoria dominant no va suposar una ampliació significativa dels marges de participació política. Doncs cal considerar que en 1446, el patrimoni fixat per accedir al càrrec de jurat segon, tercer i quart va ser de 200 lliures (4.000 sous), mentre que les magistratures únicament seran accessibles per aquells que presenten un patrimoni com a mínim de 300 lliures (6.000 sous). Per tant, durant la segona meitat de la centúria el percentatge de població que tenia la capacitat d'accedir a les eleccions tot i que podia ser major que a inicis de segle seria inferior en tot cas al $21 \%$, el que en definitiva mostra com la majoria de la població tenia l'accés tancat al govern municipal.

Per altra part, centrant-nos en la minoria política dominant, entre l'exercici polític iniciat el 1388 i el 1500 es documenta 248 famílies que ocuparen un total de 2.782 càrrecs a la vila d'Alzira, incloent-hi els càrrecs majors de justícia, jurats i mostassaf, junt als càrrecs de conseller, d'escrivà municipal i de síndic. Des de la perspectiva comparativa tot i que en sequiències cronològiques diferents, la concentració dels càrrecs estudiats a Alzira seria de 11,2 càrrecs de mitjana per llinatge superant així els 4,6 càrrecs per llinatge a la ciutat de València per al període 1346-1419 (Narbona, 1994: 21), tot i que per sota de la mitjana dels 16 càrrecs per família de la vila de Castelló per al període 1375-1500 (Viciano, 2008: 39). Dades que podrien estar revelant, a falta d'un major nombre d'estudis que així ho corroborem, com hi havia una major concentració de càrrecs per família a les viles de reialenc que no a la capital.

Amb tot, seguint els mateixos paràmetres ja assajats per la historiografia partim de la consideració inicial que els llinatges més influents de la vila serien aquells que haurien exercit més de quaranta mandats. En el cas d'Alzira aquests representen el 6,8\% dels llinatges identificats, que arribarien atresorar el $37,2 \%$ del total dels càrrecs. Aquests llinatges que podem considerar les famílies més destacades de la vila al segle XV foren els Martorell, els Gom- 
bau, els Vendrell, els Serra i els Safàbrega, que van arribar acumular en conjunt el 15,3\% dels mandats totals. Mentre que a un nivell inferior es situarien els Piquer, els Roca, els Costeia, els Jordà, els Martí i els Garcia que atresoraren cadascun al voltant dels seixanta i els cinquanta mandats. Llinatges com els Salvador, els Gilabert, els Olmedes, els Sanç, els Tolosa i els Roig van tenir una presència també destacada en el govern municipal, en tant que van exercir tots ells més de quaranta mandats, el que significa que van tenir una presència continuada.

Per altra part, la preeminència de les cinc primeres famílies esmentades també es feia evident a partir de criteris qualitatius, doncs en conjunt els Martorell, els Gombau, els Vendrell, els Serra i els Safàbrega - que representen el $2 \%$ de les famílies - desenvoluparen noranta-quatre mandats totals del càrrec de justícia i de jurat el que suposa fins el $34 \%$ d'ambdues magistratures, és a dir, més d'una quarta part dels més alts càrrecs en la jerarquia de poder municipal. Mentre que considerant únicament l'executiu de govern arribaren a ocupar el $16 \%$ dels càrrecs de la juraderia. És a dir, en la pràctica el regiment de la vila va romandre sota el control i la influència d'aquests cinc llinatges. Ara bé, el predomini d'aquestes poques famílies en el cas concret de l'executiu de govern es va desmantellar amb la implantació del sistema de sac en 1432, que va afavorir extraordinàriament la circulació de les famílies. Doncs, en termes comparatius, l'índex d'ocupació de la juraderia per família durant el sistema de redolins va ser de 3,73 places, més del doble que durant el sistema de sac, l'índex d'ocupació del qual se situa en 1,64 . Pel que fa al període en què va estar en vigència la insaculació, tot i que aquesta va permetre la introducció de noves famílies en la constitució de l'executiu de govern, es va produir novament una situació d'acumulació d'un nombre significatiu de juraderies per part de certs grups familiars, retornant així als valors anteriors que situen l'índex d'ocupació per llinatge en aquest cas al 3,48.

En aquest sentit, al capdavall les úniques famílies destacades que durant el segle XV no acusaren les modificacions del sistema d'elecció van ser els Vendrell i els Martorell que van desenvolupar la juraderia al llarg de tot el Quatrecents. Front a ells, els Serra van veure allunyar-se la seua participació en l'executiu de govern amb la introducció del sistema de sac i, posteriorment, per la insaculació. De fet, de les seues onze juraderies desenvolupades al llarg del segle XV, van ocupar sols una durant el sistema de sac (1432) i l'altra durant el sistema insaculatori (1455). En canvi, famílies com els Olmedes, els Piquer i els Gilabert desenvoluparan la magistratura únicament a partir de la 
introducció del sistema de sac mentre que els Roig i els Tolosa no ho feren fins a la introducció de la insaculació en 1446.

Taula I. Llinatges que desenvoluparen amb major freqüència les magistratures i càrrecs municipals entre 1388 i 150031

\begin{tabular}{|c|c|c|c|c|c|c|c|}
\hline Família & Justícia & Jurats & Conseller & Mostassaf & Escrivà & Síndic & Total \\
\hline Martorell & 12 & 13 & 67 & 10 & - & 3 & 105 \\
\hline Gombau & 4 & 12 & 64 & 9 & 6 & 7 & 102 \\
\hline Vendrell & 4 & 18 & 56 & 1 & - & 1 & 80 \\
\hline Serra & 6 & 10 & 46 & 7 & - & 1 & 70 \\
\hline Safàbrega & 6 & 9 & 46 & 2 & - & 6 & 69 \\
\hline Piquer & - & 9 & 38 & - & 12 & 2 & 61 \\
\hline Roca & 7 & 12 & 35 & 6 & - & - & 60 \\
\hline Costeia & 3 & 11 & 37 & 3 & 1 & 3 & 58 \\
\hline Martí & 2 & 8 & 37 & - & 3 & 8 & 58 \\
\hline Jordà & - & 7 & 42 & 1 & 5 & 2 & 57 \\
\hline Garcia & - & 2 & 33 & 2 & 8 & 6 & 51 \\
\hline Salvador & 1 & 8 & 22 & 2 & 8 & 7 & 48 \\
\hline Gilabert & 4 & 8 & 31 & 3 & 1 & - & 47 \\
\hline Olmedes & - & 9 & 32 & 1 & - & 2 & 44 \\
\hline Sanç, & 2 & 9 & 27 & 1 & - & 4 & 43 \\
\hline Tolosa & 1 & 9 & 22 & - & 7 & 3 & 42 \\
\hline Roig & - & 10 & 30 & 1 & - & - & 41 \\
\hline Navarro & 1 & 5 & 25 & - & 7 & 1 & 39 \\
\hline López de Pomar & 1 & 8 & 27 & 1 & - & - & 37 \\
\hline Carbonell & - & 6 & 34 & - & - & - & 37 \\
\hline Arenys & - & 6 & 28 & 2 & 1 & - & 37 \\
\hline Valero & 2 & 7 & 24 & 3 & - & - & 36 \\
\hline Saragossà & 1 & 2 & 24 & - & 7 & 2 & 36 \\
\hline Garí & - & 6 & 24 & 1 & 1 & 3 & 35 \\
\hline
\end{tabular}

31 En aquesta relació cal recordar que manquen fins a vint-i-quatre exercicis polítics, veure nota 7. 
Per altra part, el càrrec de conseller mostra un índex d'ocupació en torn als 8,4 càrrecs per família entre 1388 i 1500, mostrant però la sincronia entre les tres famílies que desenvoluparen en un major nombre l'executiu de govern en la mateixa cronologia. ${ }^{32}$ Doncs els membres de la família Martorell, dels Gombau i dels Vendrell en conjunt arribarien acumular gairebé el 10\% del total de les places de conseller. Òbviament, cal tenir en compte ací que almenys des de 1432 tots aquells que ocupaven la juraderia automàticament l'any següent eren consellers, però en tant que el nombre de vegades que foren consellers supera extraordinàriament el nombre de juraderies desenvolupades no seria un fet que hagués esdevingut decisiu. Igualment, una anàlisi per períodes permet confirmar les mateixes dinàmiques que havíem enunciat en la juraderia, doncs com els Vendrell i els Martorell independentment del sistema d'elecció aconseguiran reproduir-se en aquest cas entre els consellers, mentre que a partir de 1432 s'iniciaria l'ascens dels Gombau. Doncs, els membres d'aquesta família únicament havien exercit setze càrrecs de conseller al llarg dels quaranta-quatre anys polítics compresos entre 1388 i 1432, moment a partir del qual la seua presència en el consell és assídua com mostren els cinquanta-dos càrrecs de consellers desenvolupats des d'aleshores fins a 1500 . Un procés invers, sofririen els Arenys la presència dels quals com a consellers es veuria reduïda a la meitat al igual que va ocórrer amb la família Serra.

La consideració d'aquestes dades exclusivament des de la perspectiva familiar ofereixen una visió limitada de la realitat, en tant que algunes persones individualment tingueren una participació molt notòria. Partint de la consideració inicial que una persona que hagués exercit vint mandats hauria mantingut una presència més o menys continuada en el govern municipal (Viciano, 2008: 39), a la vila d'Alzira es plantegem dues situacions destacades. ${ }^{33}$ Per una part, la majoria dels individus que superen els vint mandats ho feren a partir de 1446 i, per altra part, gairebé tots tenen en comú la seua formació socioprofessional, eren notaris. Tenint en compte aquestes dues consideracions generals, es podem destacar principalment les trajectòries polítiques excepcionals de tres individus situats pel nombre de càrrec exercits dins de l'elit

32 Aquest índex d'ocupació ha estat extret de dividir els 1980 mandats anuals de conseller documentats en el període comprés entre 1388 i 1500 per les 233 famílies documentades per a la conselleria en el mateix període.

33 Al voltant de la consideració per individus cal assenyalar que tenim serioses dificultats per identificar els membres pertanyents a una mateixa família, en concret per diferenciar quan es tracta del pare o del fill en casos de nom homònim en què no hi han apel·latius (com major o menor de dies, sènior o junior) i en què no hi ha una ruptura dintre de la seqüència cronològica d'una família en l'exercici de càrrecs públics. 
del grup polític local. El primer d'ells, en tant que presenta un major nombre de càrrecs desenvolupats, fou el notari Joan Salvador qui entre 1439 i 1489 va exercir un total de trenta-vuit càrrecs anuals. ${ }^{34}$ Igualment amb un nombre important de mandats anuals es situa el notari Joan Tolosa, qui va desenvolupar trenta-un mandats al llarg dels trenta anys de desenvolupament de càrrecs públics ${ }^{35}$ Altre cas rellevant, tot i que a un nivell inferior de càrrecs respecte als dos anteriors, és el del notari Antoni Valero qui va desenvolupar vint-i-un càrrecs entre 1439 i 1485, iniciant així una trajectòria política que es va consolidar amb els seus descendents ja en el segle XVI, centúria en què els Valero són documentats com a caps de bàndol (Martínez, 2011/2: 5).$^{36}$ Tots tres individus presenten la particularitat que les seues famílies no es trobem situades entre els estrats superiors dels llinatges més influents, el que és un exemple paradigmàtic de la introducció de nous individus en la societat política vilatana com a conseqüència del inici d'un intervencionisme més decidit de la monarquia en la política local. Al capdavall, el que es posa de manifest és una renovació tímida encara de les elits de la vila que s'inicia a partir de 1455-1460, una vegada consolidada la insaculació. De fet els individus i famílies emergents (com els Valero, els Garí, els Guerau, els Roig) en la segona meitat del segle XV haurien acumulat a finals de la centúria una quantitat considerable de càrrecs municipals. Al mateix temps, amb els exemples de Joan Salvador, Joan Tolosa i Antoni Valero es singularitza l'extraordinària capacitat de promoció social que atorgava la professió notarial a la vila, idea que es veu reforçada si s'adverteix com les famílies que formen part del grup dirigent tenen almenys un o dos membres dedicats a la professió.

34 Joan Salvador va desenvolupar en quinze ocasions el càrrec de conseller major (1439, 1440, 1445, $1451,1451,1455,1460,1463,1465,1475,1477,1479,1481,1483,1485,1486)$, sis càrrecs de jurat $(1441,1447,1454,1459,1464,1484)$, dos càrrecs de mostassaf $(1467,1480)$, sis càrrecs d'escrivà de la sala (1456-1458, 1465-1467), dos de síndic $(1439,1444,1447,1452,1476,1482,1486)$ al que hi ha que afegir el càrrec d'escrivà de la Cort del batle en 1471 .

35 En 1465, quan probablement tindria en torn als 25-30 anys, Joan Tolosa s'introduí per primera vegada com a conseller major, després que el seu pare de nom homònim hagués ocupat en cinc ocasions el càrrec de conseller menor $(1434,1439,1451,1456,1459)$ i en 1442 la juraderia. En 1468 Joan Tolosa va ser escollit justícia, més tard va ocupar fins a catorze vegades el càrrec de conseller major (1465, $1471,1475,1476,1478,1482,1483,1485,1486,1488,1489,1492,1493,1495,1497,1498,1500)$ i set més com a jurat $(1466,1474,1477,1481,1484,1487,1491,1496)$. També em documentat com la seua presència al govern municipal va ser complementada amb set mandats com a escrivà municipal (1478-1479, 1493-1495, 1498 i 1500) així com tres càrrecs com a síndic $(1485,1488,1492)$ i dos càrrecs com a diputat de la Generalitat.

36 Antoni Valero va desenvolupar fins a sis vegades la magistratura de jurat $(1442,1451,1460,1466,1471$, 1477), en 1439 la de justícia, el de mostassaf en 1478 i fins a catorze ocasions el càrrec de conseller major $(1440,1446,1452,1454,1457,1461,1467,1469,1472,1476,1478,1479,1482,1485)$. 


\section{L'elit oligàrquica de la vila al llarg del segle XV}

Com hem observant al llarg d'aquesta exposició tot i que les 248 famílies que alguna vegada van formar part de la societat política alzirenya entre 1388 i 1500 es poden considerar un grup relativament ampli, cal subratllar que era un grup clarament jerarquitzat. En aquest sentit, el present estudi mostra com principalment cinc famílies lideraven el grup oligàrquic, al voltant de les quals existiria una àrea d'influència pròpia capaç de generar al seu voltant relacions de parentiu o bé clientelars amb famílies també destacades dintre del grup dirigent com els Piquer, els Roca, els Costeia, els Martí, els Jordà o els Garcia, situades però en un segon esglaó per sota d'aquelles. En aquest sentit, la documentació municipal estudiada no permet traçar un esbós d'aquestes relacions, fet que condiciona a continuació a presentar únicament les trajectòries polítiques dels membres de les famílies que desenvoluparen un major nombre de magistratures i càrrecs municipals. En aquest sentit, seguidament es tractarà una sèrie de consideracions breus al voltant de cadascun dels cinc grans llinatges junt a la presentació individualitzada del desenvolupament dels càrrecs d'alguns dels seus membres, informació que en tot cas no es pot considerar definitiva sinó que està oberta a futures investigacions.

\subsection{Els Martorell}

Sens cap dubte, els Martorell foren el llinatge més poderós d'Alzira al segle $\mathrm{XV}$, podent identificar fins a disset membres de la família, pertanyents però a tres generacions diferents, desenvolupant càrrecs públics municipals. La seua preeminència política al capdavant del govern de la vila se sincronitza amb el seu estatus econòmic, doncs alguns membres d'aquesta família de cavallers i homes de paratge han estat identificats per Antoni Furió entre les majors fortunes de la vila al context dels pagaments de la peita de 1465 (Furió, 2013: 153-154). A més a més, la seua consideració social va propiciar que alguns dels seus membres desenvoluparen el càrrec de síndic de la vila en les Corts convocades per Alfons el Magnànim (Muñoz, 2004: 747-789). En un altre sentit, es desconeix qui foren els primers membres Martorell en asseure's a la vila i si aquests estaven o no relacionats originàriament amb els Martorell de Gandia. En tot cas, i sense entrar en la problemàtica d'un possible origen convers dels seus membres enunciat per Antoni Furió (2013: 153-154; 1986; 1021-1024), un primer Martorell ha destacar és Antoni de Martorell, habitant d'Alzira, el qual rebia el 2 de setembre de 1353 a València el seu nomenament 
reial com notari (Pons, 2012: 49). Es desconeix també, però, el vincle d'aquest Antoni amb els tres germans Martorell -tot i que possiblement per cronologia es tractarà del seu pare- documentats a la vila des de finals del segle XIV i durant les primeres dècades del Quatre-cents: Pere, Jaume, i Francesc.

Del primer es documenta que hi va tindre dos fills, Jaume i Pere, dels quals almenys el primer va desenvolupar durant la segona meitat del segle XV les altes magistratures municipals, les quals va alternar amb el càrrec de conseller de paratge.

Taula II. Càrrecs municipals desenvolupats pels membres de la família Martorel| ${ }^{37}$

\begin{tabular}{|c|c|c|}
\hline ANDREU & JAUME (donzell, fill de Pere) & LLUC (fill de Jaume) \\
\hline \multirow[t]{2}{*}{ 1491Conseller } & 1445 Conseller Major & 1413 Conseller \\
\hline & 1449 Justícia & 1422 Jurat \\
\hline ANTONI & 1450 Jurat & 1424 Justícia \\
\hline 1397 Conseller & 1451 Mostassaf i C. de Paratge & 1427 Conseller \\
\hline 1398 Conseller i Mostassaf & 1453 Conseller de Paratge & 1425 Conseller \\
\hline 1399 Conseller & 1454 Mostassaf & 1426 Conseller \\
\hline 1401 Conseller & 1456 Justícia & 1427 Conseller \\
\hline 1402 Conseller & 1458 Conseller de Paratge & 1428 Síndic de Corts \\
\hline 1403 Justícia & 1460 Mostassaf i C. de Paratge & $\begin{array}{l}1432 \text { Conseller i lloct. de } \\
\text { batle }\end{array}$ \\
\hline 1413 Conseller & 1464 Conseller de Paratge & 1433 Jurat \\
\hline 1414 Jurat & 1466 Conseller de Paratge & 1434 Mostassaf \\
\hline \multirow{2}{*}{\multicolumn{2}{|c|}{ 1421-1428 Batle local }} & 1435 Mostassaf i lloct. justícia \\
\hline & & $\begin{array}{l}1437 \text { C. Major i Síndic de } \\
\text { Corts }\end{array}$ \\
\hline \multicolumn{2}{|l|}{$\begin{array}{l}\text { FRANCESC (Germà de } \\
\text { Pere i Jaume) }\end{array}$} & 1438 Síndic en corts \\
\hline 1405 Jurat & JAUME & 1445 Justícia \\
\hline 1410 Jurat & 1493 Conseller de paratge & 1448 Conseller de Paratge \\
\hline \multicolumn{3}{|c|}{$\begin{array}{l}37 \text { Galceran Martorell és el germà de Joanot Martorell, l'escriptor. Al voltant de Galceran de Martorell i } \\
\text { els vincles de parentesc dels Martorell de la vila d'Alzira (Villamanzo, 1995: 39, 44, 112-113; Furió, } \\
\text { 2013: 153-154). La filiació de Perot amb Galceran apareix a les capses de la insaculació de } 1469 \\
\text { (AMA, Còdex especials, 00/4, f. 203r). Com a fills de Perot Antoni Furió documenta a Galceran i a } \\
\text { Guillem Alamany de Martorell, el qual aquest últim no ha estat inclòs a la taula II. En aquest sentit, cal } \\
\text { subratllar que Guillem Alamany de Martorell es documenta com a conseller de paratge en } 1487 \text { i 1496, } \\
\text { jurat en } 1495 \text { i mostassaf en } 1497 \text {. }\end{array}$} \\
\hline
\end{tabular}




\begin{tabular}{|c|c|c|}
\hline \multicolumn{3}{|l|}{1411 Conseller } \\
\hline 1413 Jurat & & MATEU (fill de Francesc) \\
\hline \multirow[t]{2}{*}{1419 Síndic a les Corts } & JOAN & 1439 Jurat \\
\hline & 1424 Conseller & 1440 Conseller Major \\
\hline GALCERAN & 1425 Conseller & 1443 Conseller Major \\
\hline 1458 Mostassaf & 1426 Conseller & 1446 Conseller de Paratge \\
\hline 1459 Conseller de Paratge & 1434 Conseller Major & 1447 Conseller de Paratge \\
\hline 1463 Conseller de Paratge & 1436 Conseller Major & 1449 Mostassaf \\
\hline 1465 Conseller de Paratge & 1438 Jurat & \\
\hline \multirow[t]{2}{*}{1467 Conseller de Paratge } & 1439 Conseller Major & $\begin{array}{l}\text { PERE (germà de Jaume i } \\
\text { Francesc) }\end{array}$ \\
\hline & 1446 Conseller Major & 1396 Lloctinent de Jurat \\
\hline $\begin{array}{l}\text { GUILLEM (donzell, fill de } \\
\text { Pere) }\end{array}$ & 1447 Conseller Major & 1397 Jurat \\
\hline \multirow[t]{2}{*}{1426 Conseller } & 1449 Conseller Major & 1398 Conseller \\
\hline & 1451 conseller Major & 1399 Conseller \\
\hline GUILLEM(fill de Guillem) & & 1401 Conseller \\
\hline 1443 Jurat & JOAN & 1402 Jurat \\
\hline 1444 Conseller de Paratge & 1498 Conseller Major & 1403 Conseller \\
\hline 1445 Mostassaf & & 1404 Justícia \\
\hline 1447 Justícia & & 1405 Conseller \\
\hline 1451 Conseller de Paratge & JOANOT & 1410 Conseller \\
\hline 1454 Justícia & 1494 Mostassaf i C. de Paratge & 1411 Conseller \\
\hline 1455 Conseller de Paratge & 1495 Conseller de Paratge & 1413 Conseller \\
\hline 1458 Conseller de Paratge & 1496 C. de Paratge i diputat & 1488 Conseller \\
\hline 1461 Justícia & 1498 Conseller de Paratge & 1424 C. i lloct. justícia \\
\hline \multirow[t]{2}{*}{1470 Conseller de Paratge } & & 1425 Justícia \\
\hline & & 1426Conseller \\
\hline \multicolumn{3}{|c|}{ JAUME (germà de Pere i Francesc) } \\
\hline \multicolumn{2}{|l|}{1388 Conseller } & PERE \\
\hline \multicolumn{2}{|l|}{1395 Jurat } & 1487 Jurat \\
\hline \multicolumn{3}{|l|}{1396 Síndic en Corts } \\
\hline \multicolumn{2}{|l|}{1397 Conseller } & PEROT \\
\hline \multicolumn{2}{|l|}{1398 Conseller } & 1485 Jurat \\
\hline \multicolumn{2}{|l|}{1399 Jurat } & \\
\hline
\end{tabular}

En el cas de, Jaume, el segon dels germans esmentats, també va desenvolupar entre altres càrrecs el de justícia en 1382, el de jurat en 1395 així com el de síndic de la vila en les Corts de 1396 i en 1399, any aquest últim de la seua mort en el que també formava part de la juraderia. Aquest Jaume va tenir un 
fill, Lluc de Martorell qui va destacar en l'exercici de càrrecs públics municipals entre 1413 i 1448, sent al igual que som pare síndic de la vila en les Corts celebrades els anys 1428, 1437 i 1438. Per la seua part, Francesc, l'últim dels tres germans, va formar part de l'executiu de govern en 1405, 1410 i 1413 i va ser síndic de la vila en les Corts de 1419.

Aquest Francesc es va casar amb Damiata amb qui va tenir almenys dos fills, Mateu, qui va participar en el govern municipals entre 1439 i 1449, i Catalina, que es va casar amb Galceran Martorell, germà major de l'escriptor Joanot Martorell. Amb aquest matrimoni els Martorell de Gandia, emigrats però a la ciutat de València, s'entroncaven o bé tornaven a reforçar els seus vincles -en cas que ja hagueren estats units originàriament-amb els Martorell d'Alzira. Doncs, casat i amb residència en la vila el propi Galceran va desenvolupar càrrecs públics entre almenys 1458 i 1467, anys en què va pledejar amb el consell per motius de les eleccions de mostassaf de 1458. Anys més tard, qui va desenvolupar càrrecs en l'administració municipal va ser Perot de Martorell, fill de dit Galceran i Catalina, qui va ser jurat en 1485, conseller de paratge en diverses ocasions i diputat de la Generalitat en 1496. Per altra part, hi ha altres membres de la família Martorell (Andreu, Antoni, Guillem, Joan, i Joanot) que tot i no documentar el seu vincle familiar també van desenvolupar importants càrrecs municipals.

\subsection{Els Gombau}

Per la seua part, la família Gombau és la que experimenta un major ascens social a partir del major intervencionisme reial. Doncs, aquest llinatge d'homes de vila arrelats a la professió notarial va aconseguir a finals de la centúria que els seus membres formaren part del estament de cavallers i generosos. Com ocorria en el cas dels Martorell, el primer Gombau documentat és Pere Gombau, veí d'Alzira, qui el 12 de gener de 1358 va ser nomenat per manament reial notari (Pons, 2012: p. 51). A partir de 1397 es documenta a Guillem qui després d'uns anys com conseller aconseguiria formar part de l'executiu de govern en 1414, any en què el seu fill notari i de nom homònim ocupava la magistratura del justícia. Aquest últim va estar nomenat notari per manament reial en 1405 i no seria fins a 1413 quan iniciaria una dilatada carrera política que coincidiria en el desenvolupament de càrrecs municipals d'altres dos membres de la família, Galceran i Joan (notari), dels quals es desconeix el seu parentiu (Pons, 2014). Dit Galceran ocuparia llocs dins de l'administració mu- 
nicipal durant gairebé tots els anys compresos entre 1437 fins a 1466, entre els quals va exercir com a síndic de la vila en les Corts de 1443, 1444, 1445 i 1446. En 1470 aconseguiria promocionar de grau sent col-locat en les eleccions en la capsa d'homes generosos, un any abans què ho fera també el seu fill de nom homònim. Pel que fa Joan Gombau, aquest va exercir càrrecs en el govern entre 1435 i 1479 coincidint en l'executiu de govern en 1470 amb el seu fill de nom homònim, que també va destacar en l'exercici de càrrecs públics. Finalment, en la mateixa cronologia que Joan Gombau, menor, es documenta altre notari Pere Gombau, qui va passar en pocs anys de ser introduït en la capsa de jurat terç i quart en 1469 a estar en la capsa de generosos.

Taula III. Càrrecs polítics desenvolupats pels membres de la família Gombau

\begin{tabular}{|c|c|c|}
\hline GALCERAN (major) & GUILLEM (menor, notari) & JOAN (menor) \\
\hline 1431 Conseller & 1413 Conseller & 1470 Jurat \\
\hline 1437 Conseller Major & 1414 Justícia & 1471 Conseller Major \\
\hline 1440 Conseller Major & 1421 Síndic & 1472 Mostassaf \\
\hline 1441 Jurat & 1422 Conseller & 1475 Jurat \\
\hline 1442 Mostassaf & 1424 Conseller & 1476 Conseller Major \\
\hline 1443 Síndic en Corts & 1425 Conseller & 1477 Conseller Major \\
\hline 1444 C. Major i Síndic en Corts & 1427 Conseller & 1481 Conseller Major \\
\hline 1445 Síndic en les Corts & 1428 Conseller & 1485 Conseller Major \\
\hline 1446 Mostassaf i Síndic en Corts & 1429 Conseller & 1489 Conseller Major \\
\hline 1448 Conseller Major & 1430 Conseller & 1493 Conseller Major \\
\hline 1450 Lloctinent del Batle & 1431 Jurat & 1489 Clavari \\
\hline 1451 Conseller Major & 1434 Conseller & \\
\hline 1453 Conseller Major & 1435 Justícia & JOANOT \\
\hline 1455 Conseller Major & 1436 Conseller Major & 1491 Conseller Major \\
\hline 1459 Lloctinent de Batle & 1440 C. Major i Mostassaf & \\
\hline 1463 Lloctinent de Batle & 1441 Jurat & PERE (notari) \\
\hline 1465 Jurat & 1445 Conseller Major & 1412 Conseller \\
\hline \multirow[t]{2}{*}{1466 Conseller Major } & 1439 Conseller Major & \\
\hline & 1447 Conseller Major & PERE \\
\hline GALCERAN (menor, donzell) & 1449 Conseller Major & 1459 Conseller d'Algemesi \\
\hline 1465 Conseller Major & 1452 Conseller Major & \\
\hline
\end{tabular}


Sandra Bernabeu Borja

\begin{tabular}{|c|c|c|}
\hline 1470 Conseller Major & 1455 Conseller Major & PERE (notari) \\
\hline 1471 Justícia & 1455 Conseller Major & 1467 Jurat \\
\hline 1472 Conseller de Paratge & 1457 Mostassaf & 1468 Conseller Major \\
\hline 1473 Jurat & 1458 Conseller Major & 1469 Escrivà Municipal \\
\hline 1474 Conseller de Paratge & & 1470 Escrivà Municipal \\
\hline 1475 C. de Paratge i lloct. Justícia & JOAN (major, notari) & 1471 Escrivà Municipal \\
\hline 1476 Justícia & 1435 Conseller Menor & 1482 Conseller de Paratge \\
\hline 1477 C. de Paratge i Mostassaf & 1439 Conseller Menor & 1485 Mostassaf \\
\hline 1479 Mostassaf & 1445 Conseller Menor & 1490 Conseller de Paratge \\
\hline 1481 Conseller de Paratge & 1455 Conseller Menor & 1495 Conseller de Paratge \\
\hline 1483 Conseller de Paratge & 1463 Conseller Major & \\
\hline 1485 Lloct. Justícia & 1464 Síndic & \\
\hline 1486 Justícia & 1465 Jurat & \\
\hline 1491 Conseller de paratge & 1469 Conseller Major & \\
\hline \multirow[t]{2}{*}{1493 Conseller de Paratge } & 1470 Jurat & \\
\hline & 1471 C. Major i Síndic & \\
\hline GUILLEM (major) & 1474 Jurat & \\
\hline 1397 Conseller & $\begin{array}{l}1475 \text { C. Major/ Escrivà } \\
\text { Municipal }\end{array}$ & \\
\hline 1401 Conseller & 1476 Escrivà Municipal & \\
\hline 1413 Conseller & 1477 Conseller Major & \\
\hline 1414 Jurat & 1479 Conseller Major & \\
\hline
\end{tabular}

\subsection{Els Vendrell}

Altra família de prohoms de vila que va destacar sobre la resta fou la família Vendrell, en la que identifiquem catorze membres desenvolupant les principals magistratures i càrrecs municipals.

El primer Vendrell que identifiquen es Berenguer qui almenys va exercir la magistratura de jurat en 1378 i la de justícia en 1396 i 1399. Per altra part, almenys dos membres d'aquesta família hi eren notaris Miquel Vendrell, qui va rebre la seua carta de notaria en 1379 (Pons, 2012: 66), i catorze anys després ho faria el seu fill Antoni (Pons, 2012: 83), qui va exercir com a escrivà de la sala en 1396 i 1397. L'altre fill Miquel es documenta com conseller entre 1428 i 1430. Per la seua part, Joan Vendrell, major, fou l’únic de la família que 
va ser nomenat síndic de la vila per a unes Corts, en el seu cas les de 1419. Finalment, si hi ha un membre d'aquesta família que en destaca aquest és Miquel Vendrell, l'apotecari, qui va desenvolupar entre 1469 i 1498 un total de vint-i-tres càrrecs de duració anual, accedint en vuit ocasions a la juraderia mentre que la resta de mandats foren com a conseller major.

En conjunt, es indiscutible la preeminència social d'aquesta família que durant el segle XVI continuarà ocupant llocs dintre del govern municipal. Doncs, els descendents dels Vendrell del Quatre-cents, Joan, Onofre i Miquel participaran en els enfrontaments de bàndols entre el partit encapçalat pel Valero i l'encapçalat pels Lluquí, el que els portarà a més a més a enfrontar-se directament amb els Guerau - altra família destacada des de la segona meitat del segle XV - amb la que tingué que signar pau i treva en 1534 (Martínez, 2011/12: 5).

Taula IV. Càrrecs desenvolupats pels membres de la família Vendrell ${ }^{38}$

\begin{tabular}{lll}
\hline ANTONI (notari) & BERNAT & 1444 Jurat \\
1396 Escrivà municipal & 1422 Jurat & 1445 Conseller Major \\
1397 Escrivà municipal & 1425 Conseller & \\
1404 Conseller / lloct. Jurat & 1427 Conseller & MIQUEL (notari) \\
1410 Jurat & 1428 Conseller & 1388 Conseller \\
& 1429 Conseller & $1396-1413$ Batle local \\
ANTONI & & \\
1432 Conseller & CARLES (pare de Miquel) & MIQUEL \\
1451 Conseller Major & 1448 Mostassaf & 1427 Conseller \\
& 1450 Justícia & 1430 Conseller \\
BERENGUER & 1451 Conseller Major & \\
1362 Lloct. Del Justícia & & MIQUEL (fill de Carles) \\
1378 Jurat & GUILLEM & 1469 Conseller Major \\
1388 Conseller & 1413 Justícia & 1475 Conseller Major \\
1396 Justícia & & MIQUEL (Apotecari) \\
1397 Conseller & JOAN (major) &
\end{tabular}

38 Cal advertir que en el cas dels Miquel Vendrell, la majoria de vegades la font municipal no específica de quin Miquel Vendrell es tracta si del fill de Carles o de l'apotecari. En aquest cas, hem considerat que quan no especificava es referia a Miquel Vendrell, en tant que sota el nostre criteri és a Miquel Vendrell, fill de Carles, a qui interessava diferenciar del primer. 
Sandra Bernabeu Borja

\begin{tabular}{lll} 
1399 Conseller / Justícia & 1404 Jurat & 1469 Jurat \\
1403 Conseller & 1405 Conseller & 1470 Conseller Major \\
& 1410 Conseller & 1471 Conseller Major \\
BERENGER & 1411 Conseller & 1473 Jurat \\
1431 Conseller & 1412 Justícia & 1474 Conseller Major \\
1434 Conseller Menor & 1419 Síndic en les Corts & 1476 Conseller Major \\
1439 Conseller Menor & 1422 Jurat & 1485 Conseller Major \\
1443 Sots-Síndic & 1424 Conseller / Lloct. del Justícia & 1486 Conseller Major \\
1444 Conseller Menor & 1429 Conseller / Lloct. de Jurat & 1489 Conseller Major \\
1447 Conseller Major & 1430 Jurat i Compt. del General & 1478 Jurat \\
1450 Conseller Major & & 1479 Conseller Major \\
1452 Conseller Major & JOAN (menor) & 1481 Jurat \\
1454 Conseller Major & 1425 Conseller & 1482 Conseller Major \\
1457 Conseller Major & 1426 Jurat & 1483 Conseller Major \\
1464 Conseller Major & 1427 Conseller & 1484 Jurat \\
1466 Conseller Major & 1428 Conseller & 1491 Jurat \\
1470 Conseller Major & 1429 Jurat & 1492 Conseller Major \\
1476 Conseller Major & 1431 Conseller & 1493 Conseller Major \\
BERENGUER & 1432 Conseller (de Guasassuar) & 1495 Conseller Major \\
1494 Jurat & 1435 Justícia & 1496 Conseller Major \\
1495 Conseller Major & 1438 Jurat & 1497 Jurat \\
\hline & 1441 Conseller Major & 1498 Conseller Major \\
& 1443 Lloctinent de Justícia & \\
\hline & & \\
& &
\end{tabular}

\subsection{Els Serra}

Per la seua part, els Serra és una família que ja al segle XIV es identificada com una de les més poderoses de la vila d'Alzira. Doncs, al seu desenvolupament de càrrecs municipals cal afegir que fou una de les principals creditores de la vila com mostra l'estudi d'Andrés Díaz, qui identifica als Serra com una de les famílies a les quals a les altures de 1380 el municipi devia abonar un major nombre d'interessos per la compra de censals. (Díaz, 1994: 179-224). Al segle XV, almenys durant la primera meitat, els seues membres formaren 
part del selecte grup de persones que encapçalava el govern municipal. Entre aquests membres, en va destacar Pere, notari qui durant la segona meitat del Tres-cents i malgrat la manca de documentació ja s'adverteix com una de les persones més influents de la vila, aconseguint la consideració de donzell. Doncs, es documenta com va ser jurat almenys en 1353, 1359 i 1376, així com justícia en 1386. Durant aquests anys es va casar amb Elisenda Roca, germana de Guillem Roca qui seria també un dels individus més poderosos i influents de la vila com així ho revela la seua trajectòria política, constituïda per haver desenvolupat el càrrec de justícia en 1381 i 1396, el de jurat en 1386, 1403, 1422, el de mostassaf en 1397, el conseller 1388, 1397, 1399, 1401, 1402, 1404, 1405, 1410, 1411, 1412 i el d'obrer de les obres comunes de la vila en 1390 que van estar arrodonits per haver sigut el síndic de la vila en la comissió de les Corts de $1401 .{ }^{39}$ Per altra part, Pere Serra i Elisenda Roca van tenir cinc fills, Arnau, Berenguer, Mateu, Joan i Jaume que també van seguir els passos del seu pare en el desenvolupament de càrrecs públics municipals.

Taula V. Càrrecs desenvolupats pels membres de la família Serra

\begin{tabular}{lll}
\hline ARNAU & JAUME (fill de Pere, notari) & JOAN (fill de Pere, notari) \\
1386 Jurat & 1413 Conseller & 1386 Jurat \\
1411 Jurat & 1421 Mostassaf & 1394 Mostassaf \\
1413 Jurat & 1422 Conseller & 1396 Jurat \\
1421 lloct. del Justícia & 1424 Conseller & 1397 Conseller \\
1425 Conseller & 1425 Conseller & \\
1427 Conseller & 1426 Conseller & MATEU (donzell, fill de Pere) \\
& 1427 Jurat & 1401 Justícia \\
BARTOMEU & 1428 Conseller & 1405 Conseller \\
1401 Conseller & 1429 Conseller & 1412 Jurat \\
1402 Conseller & 1430 Mostassaf & \\
1410 Justícia & 1432 Conseller / Mostassaf & PERE (cavaller) \\
& 1431 Conseller & 1435 Conseller de Paratge \\
BARTOMEU & 1433 Conseller Major & 1436 Lloct. de Justícia \\
1433 Justícia & & 1438 Mostassaf \\
& JOAN (fill d'Arnau) & 1440 Conseller de Paratge \\
BERENUGER & 1396 lloct. de jurat & 1448 Conseller de Paratge
\end{tabular}

39 Al voltant del parentesc de Elisenda Roca amb Guillem vegeu Archivo de Protocolos Notariales del Patriarca, protocol de Innocenci de Moya (1420), ref. 25172, primer acte. 
Sandra Bernabeu Borja

1377 Lloctinent del Justícia
1387 Majordom dels Jurats
1395 Jurat
1397 Lloctinent de Jurat
1398 Conseller
1399 Conseller
1402 Conseller
1403 Conseller i síndic
1404 Jurat
1405 Conseller
1410 Conseller
1411 Jurat
1412 Conseller
1422 Conseller

1397 Conseller
1398 Conseller
1399 Justícia
1401 Conseller
1402 Jurat
1403 Conseller
1404 Conseller
1410 Conseller
1421 Justícia
1426 Conseller
1431 Conseller
1432 Jurat
1433Conseller de Paratge
1434 Conseller de Paratge
1436 Justícia

1450 Conseller de Paratge

1452 Conseller de Paratge

1454 Conseller de Paratge

1455 Jurat

1456 Conseller de Paratge

1457 Conseller Paratge

1458 Justícia

1466 Conseller Paratge

PERE (notari)

1353 Jurat

1359 Jurat

1376 Jurat

1386 Justícia

BERNAT

1330 Jurat

1411 Conseller (llauradors)

1412 Conseller

\subsection{Els Safàbrega}

Finalment, el llinatge dels Safàbrega segueix la tendència general de la família Gombau en tant que el seus inicis estan vinculats amb l'exercici de la professió notarial a partir de la qual a finals del segle XV algun dels seus membres aconsegueix la consideració de donzell. Així doncs, el primer Safàbrega documentat es Bernat qui va rebre la seua carta de notaria en 1358 i a qui trobem almenys des de 1373 fins a 1405 desenvolupant altes magistratures que completa amb el càrrecs de conseller, escrivà municipal i síndic. Anys més tard, el 10 de febrer de 1390 es documenta el nomenament com a notari reial de nova creació d'altre Safàbrega, en aquest cas Antoni, qui presumiblement per la cronologia podia ser el fill del dit Bernat. Aquest Antoni, tan sols una dècada després d'haver estat nomenant notari el trobem com a jurat de vila en 1398 i l'any posterior conseller. Ara bé si hi ha un membre de la família que en va destacar fou Joan Safàbrega, que a part de la seua dilatada carrera política al llarg de quaranta anys va ser fins en tres ocasions síndic de la vila en Corts $(1435,1437$ i 1438). Altres dos membres de la família també en destacarien, Bernat qui va desenvolupar un total de divuit càrrecs al llarg de la 
seua vida així com altre Bernat, donzell, qui des de 1457 apareix ja com a conseller de paratge aconseguint el càrrec de justícia fins en cinc ocasions $(1460,1478,1484$ i 1488).

Taula VI. Càrrecs desenvolupats pels membres de la família Safàbrega

\begin{tabular}{|c|c|c|}
\hline ANTONI (notari) & BERNAT (donzell) & JOAN \\
\hline 1397 Conseller & 1457 Conseller de Paratge & 1410 Conseller \\
\hline 1398 Jurat & 1460 Justícia & 1411 Conseller \\
\hline \multirow[t]{2}{*}{1399 Conseller } & 1463 Conseller de Paratge & 1412 Conseller \\
\hline & 1464 Justícia & 1412 Jurat \\
\hline BERENGUER & 1467 Conseller de Paratge & 1421 Jurat \\
\hline \multirow[t]{2}{*}{1459 lloct. del justícia } & 1469 C. de Paratge / Mostassaf & 1422 Conseller \\
\hline & 1477 Conseller de Paratge & 1424 Conseller \\
\hline BERNAT (notari) & 1478 Justícia & 1425 Jurat \\
\hline 1373 Jurat & 1479 Jurat & 1427 C. ./ Lloct. Jurat \\
\hline 1378 Jurat & 1480 Conseller Major & 1428 Conseller \\
\hline 1387 Escrivà Municipal & 1481 C. e Paratge / Mostassaf & 1429 Jurat \\
\hline 1388 Conseller / Justícia & 1484 Justícia & 1457 Conseller Major \\
\hline 1389 Jurat & 1487 Conseller de Paratge & 1459 Conseller Major \\
\hline 1394 Justícia & 1488 Justícia & 1460 Jurat \\
\hline 1396 Síndic & & 1461 Conseller Major \\
\hline 1397 Jurat & BERNAT (major) & 1439 Conseller Major \\
\hline 1398 Conseller /Síndic & 1422 Conseller & 1445 Conseller Major \\
\hline 1399 Conseller & 1427 Jurat & 1448 Conseller Major \\
\hline 1401 Conseller & 1428 Conseller & 1450 C. de Paratge \\
\hline 1402 Conseller & 1429 Conseller & \\
\hline 1403 Conseller & 1431 Conseller / Lloct. del Justícia & \\
\hline 1404 Conseller & 1432 Jurat & LLUÍS \\
\hline \multirow[t]{5}{*}{1405 Conseller } & 1433 Conseller Major & 1395 Justícia \\
\hline & 1434 Conseller Major & \\
\hline & 1436 Conseller Major/Lloct. de Batle & \\
\hline & 1438 Lloct del Batle & \\
\hline & 1445 Conseller Major & \\
\hline
\end{tabular}




\section{Consideracions finals}

Fins a 1283 l'accés a les magistratures i càrrecs públics municipals de la vila va ser molt restringit per al conjunt de la societat, en tant que la cooptació suposava que el prohoms designaren directament a aquells que ocuparien els oficis municipals, el que va permetre la formació i consolidació d'una oligarquia local. Amb la introducció del mètode de redolins es va produir una lleugera obertura de les eleccions respecte al sistema anterior. Doncs tot i la intervenció de l'atzar, el cert és que per a ser introduït en el bací d'aigua per al posterior sorteig calia haver estat prèviament tret com a candidat per uns electors de la parròquia, que llavors havien estat elegits conjuntament pel justícia, els jurats i el consell en una reunió on deurien tenir preeminència les opcions dels grups dominants. A aquest procés de designació indirecta de les magistratures s'unia el fet que per a la resta dels oficis es va mantindre la cooptació, per tant al remat l'accés a les eleccions continuava estant restringit i controlat per l'oligarquia. El increment del malestar en el moment de les eleccions i el conseqüent recurs a pledejar contra el govern de la vila, en un context de progressiva intervenció del poder reial a nivell municipal, va culminar amb la introducció del sistema de sacs en 1432. En la conformació de dits sacs Pere Feliu, conseller reial, va tenir total llibertat per introduir a aquells prohoms que ell va considerar oportú, per tant entre 1432 i 1446 l'oligarquia i l'accés a les eleccions havien quedat completament delimitades. Ara bé, l'aplicació d'aquest nou sistema no només a les magistratures sinó a tots els càrrecs municipals junt a l'establiment de la mesura de no tornar el redolí dins del sac una vegada havia estat nomenat per al càrrec va ser determinant per a què aquest sistema d'elecció resultarà el més participatiu que fins aleshores s'havia donat a la vila, malgrat que l'accés al sacs de les eleccions estava subjecte a la voluntat reial. Amb l'entrada en vigor del privilegi de la insaculació a partir de 1446 -interrompuda testimonialment durant dos anys per la ceda reial- es va consolidar la tendència participativa tot $i$ que amb un alt nivell de jerarquització. Doncs, la riquesa patrimonial va passar a ser la principal restricció d'accés a les eleccions alhora que el principal criteri que va contribuir a l'enquadrament dels individus dintre de la societat política de la vila.

Per altra part, l'elit política local d'Alzira al segle XV estava constituïda pels Martorell, els Gombau, els Vendrell, els Serra i els Safàbrega, que van aconseguir reproduir-se en el govern municipal durant tota la centúria. La seua preeminència social documentada - tot i que fragmentàriament al segle 
XIV - revela que es tracta d'una elit que va controlar l'accés a les magistratures i oficis municipals mitjançant el sistema de cooptació o designació directa, vigent a la vila per als càrrecs de conseller i altres oficis menors com s'ha dit fins a 1432. Tot i que l'estat actual de la investigació no permet identificar relacions clientelars ni la definició de faccions polítiques o vincles familiars en el si d'aquesta oligarquia, l'establiment però d'aquestes estratègies serien necessàries per a la seua reproducció en les institucions municipals en algun moment de la seua trajectòria. Especialment serien necessàries aquestes estratègies familiars durant la rivalitat sorgida en el moment de les eleccions, que va requerir acudir al poder reial per a resoldre qüestions davant les quals el grup dirigent local havia estat incapaç d'arribar a un consens polític.

Tanmateix, la introducció del sistema d'insaculació a partir de 1446 no va suposar cap canvi dràstic en el desenvolupament de càrrecs d'aquesta elit local, que quedava integrada en aquell sistema d'eleccions gràcies a la seua capacitat econòmica. El que si es va ressentir fou la seua capacitat d'influència $i$, en conseqüència, la seua hegemonia política en tant que ja des de 1432 havia perdut la seua facultat de cooptar als membres del consell. A partir d'aleshores dels cinc grans llinatges, únicament els Gombau experimentaran un creixement en quant a la seua presència en el desenvolupament de magistratures, èxit que va conduir a la promoció social d'alguns dels seus membres passant així de l'estament de ciutadans a generosos. Òbviament, caldran més estudis que profunditzen en aquestes cinc grans famílies així com en les seues estratègies particulars i xarxa de solidaritats mútues que els permeteren reproduirse al capdavant de les institucions municipals al llarg d'un segle i com aquesta reproducció repercutia en la pressa de decisions del govern de la vila.

Front aquesta realitat, s'observa com a partir de 1446 té lloc el inici d'un procés de renovació de les elits, que es manifesta especialment amb trajectòries polítiques brillants de certs individus durant la segona meitat del Quatre-cents. En aquest sentit, individus com Joan Tolosa, Antoni Valero o membres de la família Guerau o dels Garí, que apareixen a com individus singulars i famílies emergents dintre de la societat política vilatana durant la segona meitat del segle XV encapçalaran el govern vilatà durant centúria següent. Especialment interessant resulta el cas de la família Valero que arribaren a convertir-se en caps de bàndol al llarg del segle XVI (Martínez, 2011/12: 5).

En definitiva, a curt termini la intromissió de poder reial a la vila a partir de $1432 \mathrm{i}$, especialment en 1446, no va suposar cap ruptura en quan als llinat- 
ges que desenvoluparen un major nombre de magistratures municipals, però la superació de les relacions de parentiu i clientelars per a accedir als càrrecs municipals va donar lloc a la gestació d'una nova oligarquia i a un nou model de municipi, sorgit com a resultat de l'acció interventora de la monarquia.

\section{Referències bibliogràfiques}

ALANYA, Ll. ed. (1515). Aureum opus regalium privilegiorum civitatis et regni Valentie, Valencia, reimpr. facsímil per Diego de Gumiel, Valencia, 1972.

ARANDA, F. J. coord. (2003). Burgueses o ciudadanos en la España moderna, Universidad de Castilla-la Mancha.

BARCELÓ, M. coord. (1988). Estudis Baleàrics. Règim municipal a la Corona d’Aragó, núm. 31.

BARRIO, J. A. (2002). «Las élites políticas urbanas en la Gobernación de Orihuela: los sistemas de creación, acceso y reproducción del grupo dirigene fronterizo en el territorio fronterizo», Anuario de Estudios Medievales, 32, 777- 808.

- (1988). «La organización municipal de Alicante, siglos XIV-XV», Anales de la Universidad de Alicante. Historia medieval, 7, 137-158,

- (1992). «La introducción de la insaculación en el antiguo Reino de Valencia. Xàtiva, 1427», en Dels Furs a l'Estatut. Actes del I Congrés d'administració valenciana: de la història a la modernitat, València, 499-503.

BELENGUER, E. (1976). València en la crisi del segle XV, Barcelona, Edicions 62.

DIAZ, A. (1994). «Un intento de aproximación a la hacienda local de la Alzira medieval: el inventari dels béns de la universitat (1380)», Al-gezira, núm. 8, pp. 179224.

FALCÓN, M. I. (1988). «Origen y desarrollo del municipio medieval en el reino de Aragón», Estudis Balears, 31, 73-91.

FRADEJAS, C. i García, P. (1989). «El régimen municipal en Onda a mediados del siglo XV», Butlletí del Centre d'Estudis Municipal d'Onda, 2, 7-87.

FURIÓ, A. (1986). El camperolat valencià en l'Edat Mitjana. Demografia i economia rural en la Ribera del Xúquer (segles XIII-XVI), València, Tesi doctoral inèdita.

- (1995). Història del País Valencià, València, Alfons el Magnànim.

- (1996). «La gènesi de la fiscalitat municipal (segles XIII- XIV)», Revista d'Història Medieval, 7, 9-20.

- (2013). «"Car la retòrica se pertany més a notaris que a cavallers”. Escriptura, orgull de classe i autoria del Tirant», eHumanista, IVITRA, 4, 153-154.

- i GARCÍA-OLIVER, F. (1985). «La economía municipal a Alzira a fines del siglo XIV según un libro de cuentas de 1380-1381», En la ciudad hispánica de los siglos XIII al XVI, vol. II, pp. 1611-1634. 
FURIÓ, A. i GARCÍA-OLIVER, F. (2007). Llibre d'establiments i ordinacions de la ciutat de València, València, Universitat de València.

GARCIA-OLIVER, F. (2012). «La xarxa urbana de la Corona d'Aragó» en R. Narbona (ed), Jaume I i el seu temps 800 anys després, València, Fundació Jaume II el Just- Universitat de València, 153-168.

HUICI, A. (1916). Colección diplomática de Jaime I, el Conquistador, Valencia, Impr. Tip. Establecimiento Hijos de F. Vives Mora, (tomo I), 487-488.

IRADIEL, P. (1989). «EL segle XV. Evolució econòmica», Historia del País Valencià. De la conquesta a la federació Hispànica, Barcelona, Edicions 62, vol. 2.

LAIRÓN, A. (2001). Libre de diverses statuts e ordinacions fets pel Consell de la vila d'Algezira, València, PUV.

LÓPEZ, P. (1986). «La población en Alzira en el siglo XV», en E. Sáez, C. Segura i M. Cantera (eds.), La ciudad hispanica durante los siglos XIII al XVI, Madrid, Universidad Complutense de Madrid, 1636-1644.

NARBONA, R. (1994). «Familias y poder municipal en Valencia», en J. Hinojosa i Prades, El umbral de la modernidad. El Mediterraneoeuropeo y las ciudades en el tránsito de los siglos XIV i XVI, València, Consell Valencià de Cultura.

- (1995). Valencia, municipio medieval: poder político y luchas ciudadanas, Valencia, Ajuntament de València.

- (1996). «La complexitat de les poblacions urbanes», Història, política, societat $i$ cultural dels Països Catalans, 3, 202-217.

- (2007a). «La Corona d'Aragó al segle XV. La monarquia i els regnes» en E. Belenguer (dir.) i A. Furió (coord.), Història de la Corona d'Aragó, Barcelona, Edicions 62, vol. 1, 351- 396.

- (2007b). «Algunas reflexiones sobre la participación vecinal en el gobierno de las ciudades de la Corona de Aragón», Res Publica. Revista de Filosofía Política, $\mathrm{n}^{\mathrm{o}} 17,121-122$.

- (2013). «La configuració del perfil municipal en la xarxa urbana del regne de València (1238-1329)» en M. T. Ferrer (ed.), Jaume I. Commemoració del VIII centenari del naixement de Jaume I, Barcelona, Institut d'Estudis Catalans, vol. 2, 579-588.

MARTÍNEZ, I. (2012). En els orígens de la industria rural. L'artesanat a Alzira i la Ribera en els segles XIII-XV, València, PUV.

MARTÍNEZ, V. (2011/2). «Poder político y violencia social en la villa de Alzira. De la superación de la primera Germania a la reordenación de la insaculación a mediados del Quinientos», Revista Tiempos Modernos, 7-23.

MIRA, J. A. i VICIANO, P. (1996). «La construcció d'un sistema fiscal: municipis i impost al País Valencià (segles XIII-XIV)», La gènesi de la fiscalitat municipal (segles XIII- XIV), Revista d'Història Medieval, 7, 135-149.

MOLLÀ, E. (1987). «Apunts sobre l'Edat mitjana: oficial i càrrecs municipals a Xàtiva», Papers de la Costera, 5, 61-71. 
MOLLÀ, E. (1983). «El govern municipal de la ciutat de Xàtiva en la baixa edat mitjana» (segles XIV i XV), Xàtiva, Fira d'agost de 1983.

MUÑOZ, R. (2004). «Las Cortes de 1401-1407: Protagonistas y propuestas innovadoras de amplia repercusión en la época foral», Anuario de Estudios Medievales, 34, 747-789.

PARRA, J. P. (1984). Los Pergaminos de la Cancilleria Real del Archivo Municipal de la ciudad de Alzira, Alzira, Ajuntament d'Alzira.

PONS, V. (2012). «Los notarios valencianos en la època de Pedro IV y Juan I (13511396) Aproximación a su prosopografía», Estudis Històrics i Documents dels Arxius de Protocols, 30.

- (2014). «Me fonc donada la autoritat de notari. La consolidación de la auctoritas notariae en Valencia en el reinado de Martín el humano (1396 -1401)», en premsa.

SÁNCHEZ, M. (2003). «El sistema fiscal de los municipios catalanes y valencianos del dominio real en la Baja Edad Media», en M. Sánchez, Pagar al rey en la Corona de Aragón durante el siglo XIV, Barcelona, CSIC, Institució Milà i Fontanals, 427-459.

SANTAMARIA, A. (1981). «Los consells municipales de la Corona de Aragón mediado el siglo XIII. El sistema de cooptación», Anuario de Historia del Derecho Español, 291-364.

SERRA, M. L. (1970). «Establecimiento del régimen de insaculación a Menorca bajo el reindo de Alfonso V» en IV Congreso de la Corona de Aragón, Barcelona, ed. Anastatica, 2, 305-329.

VICIANO, P. (2008). Regir la cosa pública. Prohoms i poder local a la vila de Castelló (segles XIV $i \mathrm{XV}$ ), València, PUV.

VILLALONGA, I. (1916). Los jurados y el consejo. Régimen municipal foral valenciano, Tesis doctoral, Valencia, Banco de Valencia, 1995.

VILLAMANZO, J. (1995). Joanot de Martorell. Biografia ilustrada y diplomatario, València, Ajuntament de València. 